\title{
Characteristics and associations of pain intensity in patients referred to a specialist cancer pain clinic
}

\author{
Paulo Pina MD ${ }^{1}$, Elham Sabri MSc², Peter G Lawlor MB FRCPI MMedSc ${ }^{3,4,5}$
}

P Pina, E Sabri, PG Lawlor. Characteristics and associations of pain intensity in patients referred to a specialist cancer pain clinic. Pain Res Manag 2015;20(5):249-254.

BACKGROUND: Uncontrolled cancer pain (CP) may impair quality of life. Given the multidimensional nature of CP, its poor control is often attributed to poor assessment and classification.

OBJECTIVES: To determine the characteristics and associations of pain intensity in a specialist CP clinic.

METHODS: Consecutive patients referred to the CP clinic of the Portuguese Cancer Institute (Lisbon, Portugal) had standardized initial assessments and status documentation of the following: Brief Pain Inventory ratings for 'pain now' as the outcome variable; initial pain intensity (iPI) on a 0 to 10 scale; pain mechanism (using the Douleur Neuropathique 4 tool to assess neuropathic pain); episodic pain; Eastern Cooperative Oncology Group rating; oral morphine equivalent daily dose (MEDD); Hospital Anxiety Depression Scale and Emotional Thermometer scores; and cancer diagnosis, metastases, treatment and pain duration. Univariable analyses were conducted to test the association of independent variables with iPI. Variables with $\mathrm{P}<0.1$ were entered into a multivariable regression model, using backward elimination and a cut-point of $\mathrm{P}=0.2$ for final model selection.

RESULTS: Of 371 participants, 285 (77\%) had moderate (4 to 6) or severe (7 to 10 ) iPI. The initial median MEDD was relatively low (30 mg [range $20 \mathrm{mg}$ to $60 \mathrm{mg}]$ ). In the multivariable model, higher income, Eastern Cooperative Oncology Group rating 3 to 4, cancer diagnosis (head and neck, genitourinary and gastrointestinal), adjuvant use and initial MEDD were associated with iPI $(\mathrm{P}<0.05)$. The model's $\mathrm{R}^{2}$ was 18.6 , which explained only $19 \%$ of iPI variance.

CONCLUSIONS: The diversity of factors associated with pain intensity and their limited explanation of its variance underscore the biopsychosocial complexity of CP. Adequacy of CP management warrants further exploration.

Key Words: Assessment; Cancer pain; Opioids; Pain characteristics; Pain intensity; Pain mechanisms

\section{Les caractéristiques et les associations de l'intensité de la douleur chez les patients dirigés vers une clinique spécialisée en douleurs cancéreuses}

HISTORIQUE : La douleur cancéreuse (DC) non contrôlée peut nuire à la qualité de vie. Étant donné la nature multidimensionnelle de la DC, son piètre contrôle est souvent attribué à une évaluation et une classification médiocres. OBJECTIFS : Déterminer les caractéristiques et les associations de l'intensité de la douleur dans une clinique spécialisée en DC.

MÉTHODOLOGIE : Des patients consécutifs dirigés vers la clinique de la DC de l'institut portugais du cancer (à Lisbonne, au Portugal) disposaient d'évaluations initiales normalisées et de notes sur leur état sous les formes suivantes : classements du bref inventaire de la douleur pour la « douleur maintenant » comme variable de résultat clinique, intensité de la douleur initiale (IDi) sur une échelle de 0 à 10 , mécanisme de la douleur (au moyen de l'outil de douleur neuropathique 4), douleur épisodique, classement du groupe d'oncologie coopératif de l'Est, dose quotidienne d'équivalent de la morphine (DQÉM) par voie orale, échelle d'anxiété et scores de dépression en milieu hospitalier, thermomètre émotionnel et diagnostic de cancer, de même que les métastases, le traitement et la durée de la douleur. Les chercheurs ont réalisé des analyses univariables pour comparer l'association des variables indépendantes avec l'IDi. Les variables au $\mathrm{P}<0,1$ étaient saisies dans un modèle de régression multivariable, au moyen de l'élimination régressive et d'un seuil de $\mathrm{P}=0,2$ pour la sélection du modèle final.

RÉSULTATS : Des 371 participants, 285 (77 \%) présentaient une IDi modérée (4 à 6) à marquée (7 à 10). La DQÉM médiane initiale était relativement faible $(30 \mathrm{mg}$ [plage de $20 \mathrm{mg}$ à $60 \mathrm{mg}$ ]). Dans le modèle multivariable, un revenu plus élevé, un classement de 3 à 4 du groupe d'oncologie coopératif de l'Est, le diagnostic de cancer (tête et cou, système génito-urinaire ou gastro-intestinal), le recours à des adjuvants et la DQÉM initiale s'associaient à l'IDi $(\mathrm{P}<0,05)$. Le $\mathrm{R}^{2}$ du modèle était de 18,6 , ce qui n'expliquait que $19 \%$ de l'écart d'IDi.

CONCLUSIONS : La diversité des facteurs associés à l'intensité de la douleur et l'explication limitée des écarts font ressortir la complexité biopsychosociale de la DC. D'autres explorations s'imposent sur la pertinence de la prise en charge de la DC.

survey of 5804 patients with all stages of cancer in 11 European countries (excluding Portugal) and Israel reported that $56 \%$ suffered moderate to severe pain monthly (6). There are few literature data on cancer pain (CP) characteristics in the Portuguese population. A crosssectional survey of 164 patients, 151 (92\%) with cancer, reported that pain was assessed in 136 (83\%) and of these, 77 (57\%) had pain at the time of assessment (7).

Despite the high prevalence of pain in the cancer trajectory, a multicentre Italian study of 1801 patients (8), a vignette-related survey involving 2000 oncologists in the United States with a 32\% response rate (9), a systematic review of CP in nursing home residents (10) and a pooled review of $44 \mathrm{CP}$ management studies (11) collectively suggest ing palliative care (5), reported prevalence rates of $68.1 \%(95 \%$ $57.7 \%$ to $78.4 \%$ ) and $66.3 \%$ (95\% CI $35.8 \%$ to $83.9 \%)$, respectively. A

${ }^{1}$ Casa da Saúde da Idanha, Sintra, Portugal; ${ }^{2}$ Methods Centre, Centre for Practice-Changing Research, Ottawa Hospital Research Institute; ${ }^{3}$ Bruyère

Research Institute, Bruyère Continuing Care; ${ }^{4}$ Division of Palliative Care, Department of Medicine, and Ottawa Hospital Research Institute,

University of Ottawa, Ottawa, Ontario; ${ }^{5}$ Gulbenkian Visiting Chair in Palliative Care, Faculty of Medicine, University of Lisbon, Portugal

Correspondence : Dr Peter G Lawlor, Department of Palliative Care, 43 Bruyère Street, Ottawa, Ontario K1N 5C8.

Telephone 613-562-6262 ext 1423, fax 613-562-6371, e-mail plawlor@bruyere.org 
that $\mathrm{CP}$ is, overall, inadequately treated. Although opioids are the mainstay of CP management according to guidelines from the WHO (12), the European Society for Medical Oncology (13) and the European Association for Palliative Care (14), they are underused, especially in elderly patients $(15,16)$. Underuse is due to a mix of patient, physician, and health system and cultural factors $(9,17,18)$, including 'morphinophobia', as determined in a regional Portuguese study (19).

One of the most consistent reasons identified for poor CP management is inadequate assessment and classification of pain $(9,20,21)$. CP is multidimensional in nature, varying in physical, psychosocial and spiritual components. The patient's expression of pain, reported as pain intensity, is therefore complex (22). Younger age, neuropathic features, incident pain, psychological distress and addiction history have each been identified as predictors of longer time to achieve stable analgesia $(23,24)$. Pain intensity has been identified in some but not all studies as a predictor of the time required to achieve stable pain control $(22,23,25)$.

Given projected global demographic changes (26), and the associated increase in the number of patients with cancer (27), there is a compelling need to better understand the nature of $\mathrm{CP}$ and inform evidence-based strategies for its assessment, classification and management. The present study aimed to describe the characteristics of CP and determine the correlates and predictors of initial pain intensity (iPI) when patients were referred to a CP clinic in Portugal.

\section{METHODS}

Setting and design

The present study was conducted from June 1, 2009 to April 30, 2010 in the specialist CP clinic of the Portuguese Cancer Institute, a national tertiary-level cancer centre in Lisbon, Portugal. The study was cross-sectional in design, reflecting assessments that were conducted at subjects' first consultation in the CP clinic.

\section{Study population and eligibility criteria}

Consecutive new patient referrals to an outpatient CP clinic were approached for consent to participate in both an initial cross-sectional and a related longitudinal study of CP characteristics and management. The following eligibility criteria were applied: adult patients ( $>18$ years of age) were included if they had a cancer diagnosis, provided informed consent to study participation, and had the cognitive capacity to rate their current pain on a numerical rating scale ( 0 meaning no pain, 10 meaning the worst pain imaginable); patients were excluded if they had no evidence of active cancer or had non-cancer-related pain. CP was defined as pain directly related to malignant involvement or pain related to anticancer treatment, such as chemotherapy, radiotherapy or surgery. Ethics approval for the present study was obtained from the Research Ethics Board of the Portuguese Cancer Institute. The assembling of an electronic study dataset with numerical identifiers was approved by the Portuguese Data Protection Authority.

\section{Assessment data and tools}

Patients underwent standardized assessments and documentation of clinical data. Translated Portuguese versions of standard tools that were previously validated in English and also, in most cases, in Portuguese, were used. For ease of reporting, the Portuguese socioeconomic groupings of 1,2 and 3; 4, 5 and 6; 7 and 8; and 9 were transformed in a similar descending order to groups 1, 2, 3 and 4, respectively (28). Regarding education, primary referred to zero to four years of education; secondary referred to five to 12 years; and tertiary referred to university or $>12$ years. A history of chronic depression referred to depression preceding the cancer diagnosis and requiring ongoing antidepressant medication. In addition to a global clinical rating of functional dependency level (independent, partial or fully dependent), functional status ( 0 to $4: 0$, fully active and able to carry on all predisease performance without restriction; 4 , indicating that the patient is unable to provide self-care and confined to bed or chair) was rated using the Eastern Cooperative Oncology Group (ECOG) scale (29). Scores of $\geq 2$ on the CAGE alcohol questionnaire $(30,31)$, $\geq 4$ on a Portuguese-translated version (unpublished) of the original Short Portable Mental Status Questionnaire (32), >7 on the anxiety and depression subscales of the Hospital Anxiety and Depression Scale (HADS) (33) and $\geq 4$ on the Emotion Thermometer (ET) tool $(34,35)$ were used to screen for a history of alcohol abuse, cognitive impairment, anxiety, depression, and emotional distress, respectively.

Documentation of palliative status (in relation to the goals of treatment) was recorded when present. Cancer disease-modifying treatments (cytotoxic chemotherapy, radiotherapy or surgery) $\leq 30$ days before first CP clinic consultation were recorded. Pain data included the Brief Pain Inventory (BPI) pain intensity ratings (worst and average in the past seven days) $(36,37)$ 'pain now' as the primary outcome variable, labelled as iPI, on a 0 to 10 scale; and pain duration. CP pain mechanism was classified according to both standard clinical assessment and a DN4 score of $\geq 4$ to designate a neuropathic CP component $(37,38)$; other categories were visceral, bone and mixed. Episodic pain, defined as a transitory exacerbation of pain that occurs in addition to otherwise stable persistent pain (39), was recorded and subdivided into episodic incident pain when a trigger or incident activity was identifiable and episodic breakthrough pain when no trigger was identified. The oral morphine equivalent daily dose (MEDD) was calculated according to standard recommendations (40), and recorded along with the number of current adjuvant (pharmacological) analgesic treatments (grouped as none, and one or more).

\section{Data analyses}

SAS statistical software version 9.1 (SAS Institute Inc, USA) was used for data analysis. Means are expressed with SDs, and medians are expressed with the first to third quartile range (Q1 to Q3) unless otherwise stated. The initial MEDD was highly skewed and underwent logarithmic transformation for further analysis. With iPI as outcome, univariable analyses were conducted using the $t$ test, one-way ANOVA and Pearson correlation (r), as appropriate for independent categorical and continuous variables, respectively. Variables with $\mathrm{P}<0.1$ were entered into a multivariable regression model, using backward elimination and a cut-point of $\mathrm{P}=0.2$ for final model selection. The coefficient of determination $\left(\mathrm{R}^{2}\right)$ for the model was calculated and adjusted. Statistical significance was set at $\mathrm{P}<0.05$ for analyses.

\section{RESULTS}

Of 459 individual patient referrals to the CP clinic, 88 were excluded because of non-cancer-related pain $(n=69)$, nonactive cancer $(n=16)$ or failure to consent $(n=3)$. Demographic, psychosocial and functional status data and corresponding iPI ratings are summarized in Table 1. In the final study sample $(n=371)$, the mean age was $62.1 \pm 14.3$ years; 199 (54\%) were female. A mild cognitive deficit was detected in $46(12.4 \%)$ of patients. Approximately one-half of the study sample were classed as partially or fully dependent, and $62(16.7 \%)$ had ECOG scores of 3 or 4.

Cancer disease and pain characteristics with corresponding iPI ratings are summarized in Table 2. Of 371 patients, 263 (71\%) had metastatic disease, and $176(47 \%)$ had their treatment goal documented as palliative. The majority of cancers were solid tumours and 18 (4.8\%) hematological malignancies accounted for the remainder. Lung cancer accounted for $10(2.7 \%)$ of the cancer diagnoses.

Most pain syndromes (246 [66\%]) were mixed neuropathic and nociceptive. Using pain intensity scores derived from the BPI, the mean iPI (pain now), pain worst and pain average were mean $( \pm$ SD) scores of $5.4 \pm 2.6,7.4 \pm 2.6$ and $4.9 \pm 1.9$, respectively, and all were highly correlated $(r>0.8, P<0.0001)$. Categorizing iPI scores into conventional verbal pain intensity ratings, $86(23.2 \%), 152(41 \%)$ and $133(35.8 \%)$ of patients had mild ( 0 to 3$)$, moderate (4 to 6$)$ and severe (7 to 10) pain, respectively. The median (Q1 to Q3) pain duration was three (two to six) months. The initial median MEDD was $30 \mathrm{mg}$ (20 mg to $60 \mathrm{mg}$ ). Forty-two patients had a mean iPI of $2.55 \pm 2.33$ and were not receiving any opioid. 
TABLE 1

Demographic, psychosocial and functional status variables and their associations with initial pain intensity $(n=371)$

\begin{tabular}{|c|c|c|c|c|c|}
\hline \multirow[b]{2}{*}{ Variable } & \multirow[b]{2}{*}{ n (\%) } & \multicolumn{3}{|c|}{ Initial pain intensity } & \multirow[b]{2}{*}{$\mathbf{P}$} \\
\hline & & Mean \pm SD & Median & Q1-Q3 & \\
\hline \multicolumn{6}{|l|}{ Demographics } \\
\hline \multicolumn{6}{|l|}{ Sex } \\
\hline Male & $172(46.4)$ & $5.43 \pm 2.39$ & 6 & $4-7$ & 0.715 \\
\hline Female & $199(53.6)$ & $5.33 \pm 2.81$ & 6 & $3-7$ & \\
\hline \multicolumn{6}{|l|}{ Age, years } \\
\hline$<60$ & $146(39.4)$ & $5.23 \pm 2.77$ & 6 & $3-7$ & 0.371 \\
\hline$\geq 60$ & $225(60.6)$ & $5.48 \pm 2.52$ & 6 & $4-7$ & \\
\hline \multicolumn{6}{|l|}{ Education } \\
\hline Primary level & $259(69.8)$ & $5.47 \pm 2.60$ & 6 & $4-7$ & 0.316 \\
\hline $\begin{array}{l}\text { Secondary or } \\
\text { tertiary }\end{array}$ & $112(30.2)$ & $5.17 \pm 2.67$ & 6 & $3-7$ & \\
\hline \multicolumn{6}{|l|}{ Work status } \\
\hline Active & $47(12.7)$ & $5.11 \pm 2.79$ & 6 & $2-7$ & 0.884 \\
\hline Disability leave & $57(15.4)$ & $5.35 \pm 2.53$ & 6 & $4-7$ & \\
\hline Retired & $243(65.5)$ & $5.44 \pm 2.61$ & 6 & $4-7$ & \\
\hline Unemployed & $24(6.5)$ & $5.33 \pm 2.68$ & 6 & $3.5-7.5$ & \\
\hline \multicolumn{6}{|c|}{ Socioeconomic group } \\
\hline $1,2,3$ & $282(76.0)$ & $5.56 \pm 2.50$ & 6 & $4-7$ & 0.019 \\
\hline 4 & $89(24.0)$ & $4.81 \pm 2.91$ & 5 & $2-7$ & \\
\hline \multicolumn{6}{|l|}{ Income } \\
\hline$\leq € 485 /$ month & $176(47.4)$ & $5.06 \pm 2.71$ & 6 & $3-7$ & 0.025 \\
\hline$>€ 485 /$ month & $195(52.6)$ & $5.67 \pm 2.51$ & 6 & $4-7$ & \\
\hline \multicolumn{6}{|l|}{ Clinical history } \\
\hline \multicolumn{6}{|l|}{ Chronic depression } \\
\hline No & $349(94.0)$ & $5.37 \pm 2.61$ & 6 & $4-7$ & 0.76 \\
\hline Yes & $22(6.0)$ & $5.55 \pm 2.77$ & 6 & $3-8$ & \\
\hline \multicolumn{6}{|c|}{ Alcohol abuse history } \\
\hline No & $288(77.6)$ & $5.19 \pm 2.67$ & 6 & $3-7$ & 0.012 \\
\hline Yes & $83(22.4)$ & $6.01 \pm 2.34$ & 6 & $5-8$ & \\
\hline \multicolumn{6}{|c|}{ Drug or alcohol abuse history } \\
\hline No & $285(76.8)$ & $5.22 \pm 2.67$ & 6 & $3-7$ & 0.032 \\
\hline Yes & $86(23.2)$ & $5.91 \pm 2.40$ & 6 & $5-7$ & \\
\hline \multicolumn{6}{|l|}{ Tobacco smoking } \\
\hline Never & $268(72.2)$ & $5.45 \pm 2.67$ & 6 & $4-7$ & 0.699 \\
\hline Ex-smoker & $30(8.1)$ & $5.13 \pm 2.43$ & 6 & $4-6$ & \\
\hline Current & $73(19.7)$ & $5.22 \pm 2.53$ & 6 & & \\
\hline \multicolumn{6}{|l|}{$\begin{array}{l}\text { Functional status } \\
\text { Cognitive status }\end{array}$} \\
\hline Normal & $325(87.6)$ & $5.30 \pm 2.64$ & 6 & $4-7$ & 0.123 \\
\hline Mild deficit & $46(12.4)$ & $5.93 \pm 2.43$ & 6 & $4-7$ & \\
\hline \multicolumn{6}{|c|}{ Functional dependency } \\
\hline Independent & $192(51.7)$ & $5.01 \pm 2.74$ & 6 & $3-7$ & 0.005 \\
\hline Dependent & $179(48.3)$ & $5.77 \pm 2.43$ & 6 & $5-7$ & \\
\hline \multicolumn{6}{|l|}{ ECOG } \\
\hline $0,1,2$ & $309(83.3)$ & $5.21 \pm 2.66$ & 6 & $3-7$ & 0.007 \\
\hline 3,4 & $62(16.7)$ & $6.19 \pm 2.28$ & 6.5 & $5-8$ & \\
\hline
\end{tabular}

ECOG Eastern Cooperative Oncology Group

In the univariable analyses testing the association of iPI with categorical variables (Tables 1 and 2), a positive association was found in relation to higher income and upper socioeconomic groups (groups 1, 2 and 3); a history of drug or alcohol abuse; greater functional dependency; 'palliative' status designation; primary cancer diagnosis (the highest iPI groups were those with head and neck, gastrointestinal, and genitourinary cancer); recent radiotherapy treatment; the presence of neuropathic CP or mixed pain; presence of metastases; and use of $\geq 1$ adjuvant analgesic medication $(\mathrm{P}<0.05)$
TABLE 2

Cancer disease and pain characteristics, and their association with initial pain intensity $(n=371)$

\begin{tabular}{|c|c|c|c|c|c|}
\hline \multirow[b]{2}{*}{ Variable } & \multirow[b]{2}{*}{ n (\%) } & \multicolumn{3}{|c|}{ Initial pain intensity (iPI) } & \multirow[b]{2}{*}{$\mathbf{P}$} \\
\hline & & Mean \pm SD & Median & Q1-Q3 & \\
\hline \multicolumn{6}{|c|}{ Cancer characteristics } \\
\hline \multicolumn{6}{|l|}{ Cancer diagnosis } \\
\hline Head and neck & $92(24.8)$ & $5.73 \pm 2.22$ & 6 & $5-7$ & 0.008 \\
\hline Lung & $10(2.7)$ & $5.20 \pm 2.25$ & 4.5 & $4-7$ & \\
\hline Gastrointestinal & $82(22.1)$ & $5.62 \pm 2.69$ & 6 & $4-7$ & \\
\hline Breast & $43(11.6)$ & $5.30 \pm 3.07$ & 6 & $2-8$ & \\
\hline Genitourinary & $79(21.3)$ & $5.70 \pm 2.31$ & 6 & $5-7$ & \\
\hline Other & $65(17.5)$ & $4.26 \pm 2.91$ & 4 & $2-7$ & \\
\hline \multicolumn{6}{|l|}{ Metastatic disease } \\
\hline No & $108(29.1)$ & $4.74 \pm 2.84$ & 5 & $2-7$ & 0.003 \\
\hline Yes & $263(70.9)$ & $5.64 \pm 2.48$ & 6 & $4-7$ & \\
\hline \multicolumn{6}{|l|}{ Bone metastases } \\
\hline No & $242(65.2)$ & $5.19 \pm 2.69$ & 6 & $3-7$ & 0.059 \\
\hline Yes & $129(34.8)$ & $5.73 \pm 2.46$ & 6 & $4-7$ & \\
\hline \multicolumn{6}{|c|}{ Palliative treatment goal } \\
\hline No & $195(52.6)$ & $4.87 \pm 2.83$ & 6 & $2-7$ & $<0.0001$ \\
\hline Yes & $176(47.4)$ & $5.94 \pm 2.24$ & 6 & $5-7$ & \\
\hline \multicolumn{6}{|l|}{ Surgery } \\
\hline No & $259(69.8)$ & $5.39 \pm 2.68$ & 6 & $4-7$ & 0.922 \\
\hline Yes & $112(30.2)$ & $5.36 \pm 2.49$ & 6 & $4-7$ & \\
\hline \multicolumn{6}{|l|}{ Chemotherapy } \\
\hline No & $204(55.0)$ & $5.21 \pm 2.78$ & 6 & $3-7$ & 0.176 \\
\hline Yes & $167(45.0)$ & $5.58 \pm 2.41$ & 6 & $4-7$ & \\
\hline \multicolumn{6}{|l|}{ Radiotherapy } \\
\hline No & $195(52.6)$ & $5.11 \pm 2.92$ & 6 & $2-7$ & 0.038 \\
\hline Yes & $176(47.4)$ & $5.67 \pm 2.22$ & 6 & $4.5-7$ & \\
\hline \multicolumn{6}{|c|}{ Cancer pain characteristics } \\
\hline \multicolumn{6}{|c|}{ Nociceptive visceral } \\
\hline No & $259(69.8)$ & $5.29 \pm 2.64$ & 6 & $4-7$ & 0.349 \\
\hline Yes & $112(30.2)$ & $5.57 \pm 2.58$ & 6 & $4-7$ & \\
\hline \multicolumn{6}{|c|}{ Nociceptive soft tissue } \\
\hline No & $153(41.2)$ & $5.52 \pm 2.47$ & 6 & $3-7$ & 0.216 \\
\hline Yes & $218(58.8)$ & $5.57 \pm 2.58$ & 6 & $4-7$ & \\
\hline \multicolumn{6}{|c|}{ Nociceptive bone pain } \\
\hline No & $222(59.8)$ & $5.18 \pm 2.67$ & 6 & $3-7$ & 0.070 \\
\hline Yes & $149(40.2)$ & $5.68 \pm 2.52$ & 6 & $4-7$ & \\
\hline \multicolumn{6}{|c|}{ NeuP (DN4-positive) } \\
\hline No & $210(56.6)$ & $4.73 \pm 2.82$ & 5 & $2-7$ & $<0.0001$ \\
\hline Yes & $161(43.4)$ & $6.22 \pm 2.05$ & 6 & $5-8$ & \\
\hline \multicolumn{6}{|c|}{ NeuP (DN4-positive) or clinically mixed } \\
\hline No & $84(22.6)$ & $4.63 \pm 2.83$ & 6 & $2-7$ & 0.003 \\
\hline Yes & $287(77.4)$ & $5.60 \pm 2.52$ & 6 & $4-7$ & \\
\hline \multicolumn{6}{|l|}{ Episodic incident } \\
\hline No & $151(40.7)$ & $5.43 \pm 2.65$ & 6 & $4-7$ & 0.747 \\
\hline Yes & $220(59.3)$ & $5.34 \pm 2.60$ & 6 & $4-7$ & \\
\hline \multicolumn{6}{|c|}{ Episodic breakthrough } \\
\hline No & $212(57.1)$ & $5.17 \pm 2.77$ & 6 & $3-7$ & 0.066 \\
\hline Yes & $159(42.9)$ & $5.66 \pm 2.38$ & 6 & $4-7$ & \\
\hline Adjuvant analgesic & & & & & \\
\hline None & $161(43.4)$ & $4.87 \pm 2.79$ & 6 & $2-7$ & 0.001 \\
\hline$\geq 1$ & $210(56.6)$ & $5.77 \pm 2.42$ & 6 & $4-7$ & \\
\hline
\end{tabular}

NeuP Neuropathic pain

In the univariable analyses testing the association of iPI with continuous variables (Table 3 ), the only significant association occurred in relation to the initial MEDD $(\mathrm{P}<0.05)$, which was positive in direction. The HADS depression and anxiety subscale scores were $>10$ in 


\begin{tabular}{|c|c|c|}
\hline Variable & Correlation (r) & $\mathbf{P}$ \\
\hline HADS anxiety score & 0.04 & 0.4 \\
\hline HADS depression score & 0.06 & 0.3 \\
\hline \multicolumn{3}{|l|}{ Emotional thermometer scores } \\
\hline Distress & 0.00 & 0.9 \\
\hline Anxiety & 0.06 & 0.3 \\
\hline Depression & 0.04 & 0.5 \\
\hline Anger & -0.00 & 0.9 \\
\hline Help desired & 0.08 & 0.1 \\
\hline Duration of pain, months & 0.04 & 0.4 \\
\hline Initial morphine equivalent daily dose ${ }^{*}$ & 0.32 & $<0.0001$ \\
\hline
\end{tabular}

*Log value. HADS Hospital Anxiety and Depression Scale

$239(64.4 \%)$ and $215(57.9 \%)$ of patients, respectively, indicating abnormal levels of depression and anxiety. The ET scores were $\geq 4$ for distress, anxiety, depression, anger and help desired in $208(56 \%)$, 271 (73\%), 280 (75.5\%), $216(58.2 \%)$ and 209 (56.3\%), respectively.

In the multivariable model (Table 4), nine variables were retained and five were positively associated with iPI: higher income, ECOG ratings 3 to 4 , cancer type (head and neck, genitourinary and gastrointestinal); adjuvant use and initial MEDD $(\mathrm{P}<0.05)$. The adjusted $\mathrm{R}^{2}$ for this model was 18.6; thus, the model explained $<20 \%$ of the variance in $\mathrm{iPI}$.

\section{DISCUSSION}

Using iPI ratings recorded as 'pain now' at the first CP clinic consultation, our study showed a high correlation between this measure and those of 'pain worst' and 'pain average' over the preceding seven days, suggesting that 'pain now' has validity as a measure of patients' overall experience of pain intensity in the week preceding their initial CP clinic consultation. Our study sample was comparatively unique in that it included patients with earlier stage cancer, in addition to $47 \%$ whose treatment goals were documented as palliative. However, we have no data to verify the consistency and accuracy of this latter designation, other than indirectly inferred evidence, given that $71 \%$ had metastatic disease. Compared with other studies of pain in predominantly inpatient palliative care or hospice based populations $(7,24,37)$, our outpatient sample had a relatively high performance status; only $16.7 \%$ had ECOG scores of 3 or 4 . Furthermore, because longitudinal studies of pain intensity may generate more robust data regarding its predictors, correlates and variability $(15,38)$, this needs to be acknowledged when comparing our study findings with those of longitudinal studies $(23,25)$.

There is substantial evidence of suboptimal CP management by medical oncologists in the United States (9). The situation in Portugal is probably no different: although $77 \%$ of our study sample had pain of either moderate or severe intensity, based on their iPI ratings, the initial median (Q1 to Q3) MEDD of our sample was $30 \mathrm{mg}$ (20 mg to $60 \mathrm{mg}$ ), which is very low compared with other studies $(41,42)$, and suggestive of opioid underuse. It supports the finding of a populationbased survey of patients with chronic pain in Portugal, in which the reported prevalence rate of opioid use in those with chronic CP was $10.13 \%$ (43). This warrants further standardized evaluation using a tool such as the Pain Management Index (44).

Despite literature data supporting the association of psychosocial distress with pain intensity levels $(23,24,41)$, and despite our sample's HADS and ET scores reflecting a very high level of such distress, we surprisingly found no dimensional correlation between these and iPI. Recognizing that all of the patients in our sample had some level of $\mathrm{CP}$, it is possible that an association between $\mathrm{CP}$ and psychological distress might be more readily detected on a categorical rather than a dimensional severity basis, if we had conducted a broader population study to determine psychological distress in relation to the categorical
TABLE 4

Multivariable model to determine independent associations with initial pain intensity*

\begin{tabular}{lcl}
\hline Parameter & Estimate & Pr > t \\
\hline Intercept & 1.775 & 0.0009 \\
Income >€485/month & 0.596 & 0.02 \\
Socioeconomic groups 1,2,3 & 0.483 & 0.10 \\
Eastern Cooperative Oncology Group: 3,4 & 0.782 & 0.03 \\
Palliative status documented: Yes & 0.47 & 0.10 \\
Cancer diagnosis: head and neck & 0.867 & 0.03 \\
Cancer diagnosis: Iung & -0.087 & 0.92 \\
Cancer diagnosis: gastrointestinal & 1.054 & 0.01 \\
Cancer diagnosis: breast & 0.448 & 0.36 \\
Cancer diagnosis: genitourinary & 0.994 & 0.01 \\
Neuropathic pain (DN4-positive) or clinically & 0.506 & 0.11 \\
classed as mixed & & \\
Adjuvant use: one or more & 0.591 & 0.02 \\
Bone metastases: yes & 0.385 & 0.18 \\
Initial morphine equivalent daily dose $^{\dagger}$ & 0.426 & $<.0001$ \\
\hline${ }^{*}$ Adjusted $R^{2}$ of model = 18.6; ${ }^{\dagger}$ Log value & &
\end{tabular}

presence or absence of CP. Regarding assessment tools, we used versions of the BPI and HADS that were validated in Portuguese, as spoken in Portugal $(33,37)$. We used versions of the CAGE and ET that were validated in Brazilian Portuguese $(31,35)$ and, thus, we cannot exclude the possible contribution of interpretive error to the lack of correlation between ET scores and iPI. Other researchers have demonstrated the association between $\mathrm{CP}$ and psychological distress $(23,24,41)$, and although there is some commonality in the biological pathways that subserve depression and pain (45), studies have not been designed to determine a causal relationship in either direction (46). An association between CP intensity and a history of drug or alcohol abuse has been demonstrated in some studies $(23,24)$. Although a drug or alcohol abuse history had a statistically significant association with iPI in our univariable analysis, an independent association was not evident in the multivariable analysis. Other studies have demonstrated an association between pain intensity and episodic incident pain $(22,23,42)$; however, our study failed to demonstrate this. Although our cross-sectional study found that psychosocial distress, a history of drug or alcohol abuse, and episodic pain were not independently associated with initial pain intensity, a longitudinal analysis may be more sensitive in detecting such associations.

In our final multivariable model, the primary cancer diagnoses of head and neck, genitourinary and gastrointestinal were independent predictors of higher iPI. The relatively high prevalence $(29.2 \%)$ of neuropathic pain in the head and neck group may explain their higher iPI. Among the demographic variables, both higher income and poorer performance status were independently associated with iPI. We can only surmise that those on lower incomes may be less well able to verbalise their iPI. Our finding that iPI was associated with poorer performance status is consistent with literature data (47). Unlike other studies $(23,24)$, age was not associated with iPI in our current study. Adjuvant use was independently associated with iPi, possibly reflecting an evidence-based approach to neuropathic pain management. The strongest independent association with iPI occurred in relation to opioid dose at the point of referral, reflecting an approach that is generally consistent with current guidelines, albeit possibly inadequate in terms of actual opioid dosing.

Our study has some unique features: its knowledge synthesis contribution is significant, given the limited literature data regarding CP in a Portuguese setting; its approach involved a comprehensive combination of standardized assessments with validated tools. Our study also has significant limitations. First, the presence of a referral bias is very likely with a CP clinic, as reflected by $77 \%$ of patients having moderate or severe pain. The number of patients with lung cancer was 
relatively low at $10 \%$, whereas the number with head and neck cancer was relatively high at $24.8 \%$. Second, the cross-sectional design of our study only captures a narrow temporal window of patients' pain intensity experience. This justifies conducting a longitudinal study to obtain more robust data. Third, the $\mathrm{R}^{2}$ of the final multivariable model was 18.6 , indicating that it only explained approximately $19 \%$ of the variance in pain intensity, a finding that may reflect the known and unknown dimensions of pain intensity and further substantiates the need for a longitudinal study.

\section{CONCLUSION}

Pain intensity is associated with a heterogenous group of factors: higher income; poorer functional performance status; cancer type (head and neck, genitourinary and gastrointestinal); adjuvant use and initial opioid dose. The diversity of associations, and our study's limited explanation of pain intensity variance $(<20 \%)$, together underscore the biopsychosocial complexity of CP. The level of opioid dosing

\section{REFERENCES}

1. Te Boveldt N, Vernooij-Dassen M, Burger N, Ijsseldijk M, Vissers K, Engels Y. Pain and its interference with daily activities in medical oncology outpatients. Pain Physician 2013;16:379-89.

2. Portenoy RK, Ahmed E. Principles of opioid use in cancer pain. J Clin Oncol $2014 ; 32: 1662-70$.

3. van den Beuken-van Everdingen MH, de Rijke JM, Kessels AG, Schouten HC, van Kleef M, Patijn J. Prevalence of pain in patients with cancer: A systematic review of the past 40 years. Ann Oncol 2007;18:1437-49.

4. Seretny M, Currie GL, Sena ES, et al. Incidence, prevalence, and predictors of chemotherapy-induced peripheral neuropathy: A systematic review and meta-analysis. Pain 2014;155:2461-70.

5. Van Lancker A, Velghe A, Van Hecke A, et al. Prevalence of symptoms in older cancer patients receiving palliative care: A systematic review and meta-analysis. J Pain Symptom Manage 2014:47:90-104.

6. Breivik H, Cherny N, Collett B, et al. Cancer-related pain: A pan-European survey of prevalence, treatment, and patient attitudes. Ann Oncol 2009;20:1420-33.

7. Goncalves F, Almeida A, Antunes C, et al. A cross-sectional survey of pain in palliative care in Portugal. Support Care Cancer 2013;21:2033-9.

8. Apolone G, Corli O, Caraceni A, et al. Pattern and quality of care of cancer pain management. Results from the Cancer Pain Outcome Research Study Group. Br J Cancer 2009;100:1566-74.

9. Breuer B, Fleishman SB, Cruciani RA, Portenoy RK. Medical oncologists' attitudes and practice in cancer pain management: A national survey. J Clin Oncol 2011;29:4769-75.

10. Drageset J, Corbett A, Selbaek G, Husebo BS. Cancer-related pain and symptoms among nursing home residents: A systematic review. J Pain Symptom Manage 2014;48:699-710.e1.

11. Deandrea S, Montanari M, Moja L, Apolone G. Prevalence of undertreatment in cancer pain. A review of published literature. Ann Oncol 2008;19:1985-91.

12. World Health Organization. Cancer Pain Relief, 2nd edn. Geneva: World Health Organization, 1996.

13. Ripamonti CI, Santini D, Maranzano E, Berti M, Roila F, ESMO Guidelines Working Group. Management of cancer pain: ESMO Clinical Practice Guidelines. Ann Oncol 2012;23(Suppl 7):vii139-54.

14. Caraceni A, Hanks G, Kaasa S, et al. Use of opioid analgesics in the treatment of cancer pain: Evidence-based recommendations from the EAPC. Lancet Oncol 2012;13:e58-68.

15. Gagnon B, Scott S, Nadeau L, Lawlor PG. Patterns of communitybased opioid prescriptions in people dying of cancer. J Pain Symptom Manage 2015;49:36-44.e1.

16. Higginson IJ, Gao W. Opioid prescribing for cancer pain during the last 3 months of life: Associated factors and 9-year trends in a nationwide United Kingdom cohort study. J Clin Oncol 2012;30:4373-9.

17. Schumacher KL, Plano Clark VL, West CM, Dodd MJ, Rabow MW, Miaskowski C. Pain medication management processes used by oncology outpatients and family caregivers part II: Home and lifestyle contexts. J Pain Symptom Manage 2014;48:784-96. was likely suboptimal in patients referred to our CP clinic. Adequacy of CP treatment therefore warrants further exploration. Prospective longitudinal studies are particularly needed to better understand CP, such as the contribution of neuropathic and other challenging components, and thus inform its classification and management.

DISCLOSURES: In the past five years, Dr Pina received honoraria from Laboratórios Vitória, S.A. Portugal and Grünenthal, S.A. Portugal. He is on the Speaker's Bureau for Grünenthal, S.A. Portugal.

ACKNOWLEDGEMENTS: The authors acknowledge the support of the Ottawa Hospital Research Institute in data analysis, and the University of Lisbon and the Gulbenkian Foundation for funding a visiting academic appointment for Peter Lawlor with the University of Lisbon.

Presented at the 8th World Research Congress of the European Association for Palliative Care, Lleida, Spain, June 5 to 7, 2014.

18. Schumacher KL, Plano Clark VL, West CM, Dodd MJ, Rabow MW, Miaskowski C. Pain medication management processes used by oncology outpatients and family caregivers part I: Health systems contexts. J Pain Symptom Manage 2014;48:770-83.

19. Verloo H, Mpinga EK, Ferreira M, Rapin CH, Chastonay P. Morphinofobia: The situation among the general population and health care professionals in North-Eastern Portugal. BMC Palliat Care 2010;9:15-684X-9-15

20. Knudsen AK, Aass N, Fainsinger R, et al. Classification of pain in cancer patients - a systematic literature review. Palliat Med 2009;23:295-308.

21. Oldenmenger WH, Sillevis Smitt PA, van Dooren S, Stoter G, van der Rijt CC. A systematic review on barriers hindering adequate cancer pain management and interventions to reduce them: A critical appraisal. Eur J Cancer 2009;45:1370-80.

22. Fainsinger RL, Fairchild A, Nekolaichuk C, Lawlor P, Lowe S, Hanson J. Is pain intensity a predictor of the complexity of cancer pain management? J Clin Oncol 2009;27:585-90.

23. Fainsinger RL, Nekolaichuk C, Lawlor P, et al. An international multicentre validation study of a pain classification system for cancer patients. Eur J Cancer 2010;46:2896-904.

24. Fainsinger RL, Nekolaichuk CL, Lawlor PG, Neumann CM, Hanson J, Vigano A. A multicenter study of the revised Edmonton Staging System for classifying cancer pain in advanced cancer patients. J Pain Symptom Manage 2005;29:224-37.

25. Mercadante S, Gebbia V, David F, et al. Does pain intensity predict a poor opioid response in cancer patients? Eur J Cancer 2011;47:713-7.

26. Christensen K, Doblhammer G, Rau R, Vaupel JW. Ageing populations: The challenges ahead. Lancet 2009;374:1196-208.

27. World Health Organization. Cancer Fact Sheet No297. <www.who. int/mediacentre/factsheets/fs297/en/index.html> (Accessed February 18, 2015).

28. Classificação Nacional de Profissões. 2. a edição. Lisboa. Direccão de Serviços de Avaliação e Certificação, Instituto do Emprego e Formação Profissional. 2001. ISBN: 972-732-146-1

29. Oken MM, Creech RH, Tormey DC, et al. Toxicity and response criteria of the Eastern Cooperative Oncology Group. Am J Clin Oncol 1982;5:649-55.

30. Ewing JA. Detecting alcoholism. The CAGE questionnaire. JAMA 1984;252:1905-7.

31. Masur J, Capriglione MJ, Monteiro MG, Jorge MR. Detecção precoce do alcoolismo em clínica médica através do questionário CAGE: utilidade e limitações. J Bras Psiquiatr 1985;34:31-4.

32. Pfeiffer E. A short portable mental status questionnaire for the assessment of organic brain deficit in elderly patients. J Am Geriatr Soc 1975;23:433-41.

33. Pais-Ribeiro J, Silva I, Ferreira T, Martins A, Meneses R, Baltar M. Validation study of a Portuguese version of the Hospital Anxiety and Depression Scale. Psychol Health Med 2007;12:225-35.

34. Mitchell AJ, Baker-Glenn EA, Granger L, Symonds P. Can the Distress Thermometer be improved by additional mood domains? 
Part I. Initial validation of the Emotion Thermometers tool. Psychooncology 2010;19:125-33.

35. Decat CS, Laros JA, Araujo TC. Termômetro de Distress: validação de um instrumento breve para avaliação diagnóstica de pacientes oncológicos. Psico-USF 2009;14:253-60.

36. Cleeland CS, Ryan KM. Pain assessment: Global use of the Brief Pain Inventory. Ann Acad Med Singapore 1994;23:129-38.

37. Azevedo LF, Costa-Pereira A, Dias C, et al. Tradução, adaptação cultural e estudo multicêntrico de validação de instrumentos para rastreio e avaliação do impacto da dor crónica. Pain (Portugal) 2007;15:6-56. < www.aped-dor.org/images/revista_dor/pdf/2007/n4.pdf>.

38. Bouhassira D, Attal N, Alchaar H, et al. Comparison of pain syndromes associated with nervous or somatic lesions and development of a new neuropathic pain diagnostic questionnaire (DN4). Pain 2005;114:29-36.

39. Mercadante S, Radbruch L, Caraceni A, et al. Episodic (breakthrough) pain: Consensus conference of an expert working group of the European Association for Palliative Care. Cancer 2002;94:832-9.

40. Pereira J, Lawlor P, Vigano A, Dorgan M, Bruera E. Equianalgesic dose ratios for opioids. A critical review and proposals for long-term dosing. J Pain Symptom Manage 2001;22:672-87.
41. Knudsen AK, Brunelli C, Kaasa S, et al. Which variables are associated with pain intensity and treatment response in advanced cancer patients? Implications for a future classification system for cancer pain. Eur J Pain 2011;15:320-7.

42. Knudsen AK, Brunelli C, Klepstad P, et al. Which domains should be included in a cancer pain classification system? Analyses of longitudinal data. Pain 2012;153:696-703.

43. Azevedo LF, Costa-Pereira A, Mendonca L, Dias CC, CastroLopes JM. A population-based study on chronic pain and the use of opioids in Portugal. Pain 2013;154:2844-52.

44. Greco MT, Roberto A, Corli O, et al. Quality of cancer pain management: An update of a systematic review of undertreatment of patients with cancer. J Clin Oncol 2014;32:4149-54.

45. Bair MJ, Robinson RL, Katon W, Kroenke K. Depression and pain comorbidity: A literature review. Arch Intern Med 2003;163:2433-45.

46. Laird BJ, Boyd AC, Colvin LA, Fallon MT. Are cancer pain and depression interdependent? A systematic review. Psycho-Oncology 2009;18:459-64.

47. Mercadante S, Guccione C, Di Fatta S, et al. Cancer pain management in an oncological ward in a comprehensive cancer center with an established palliative care unit. Support Care Cancer 2013;21:3287-92. 


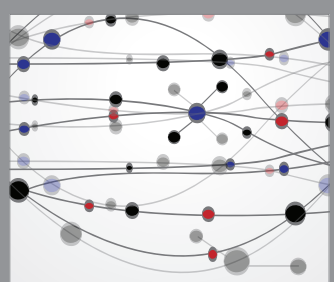

The Scientific World Journal
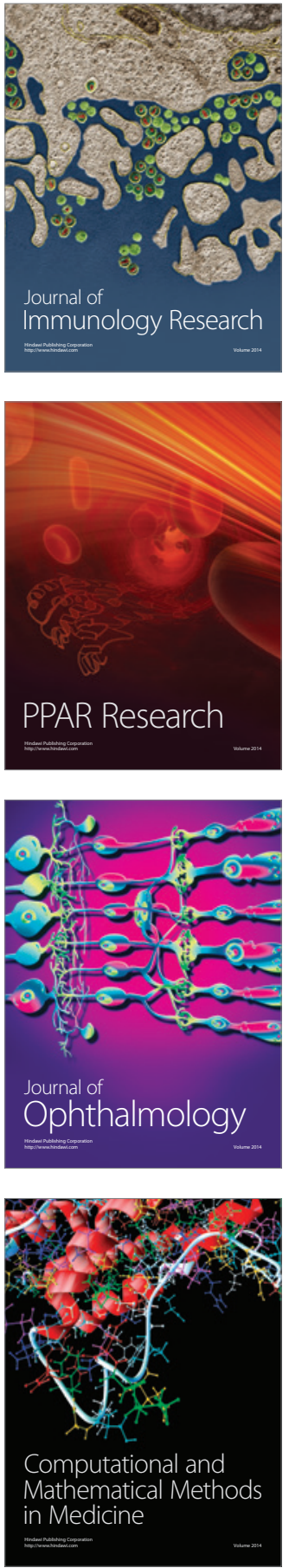

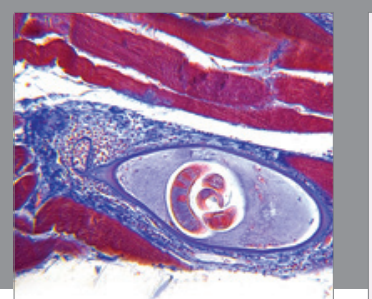

Gastroenterology Research and Practice

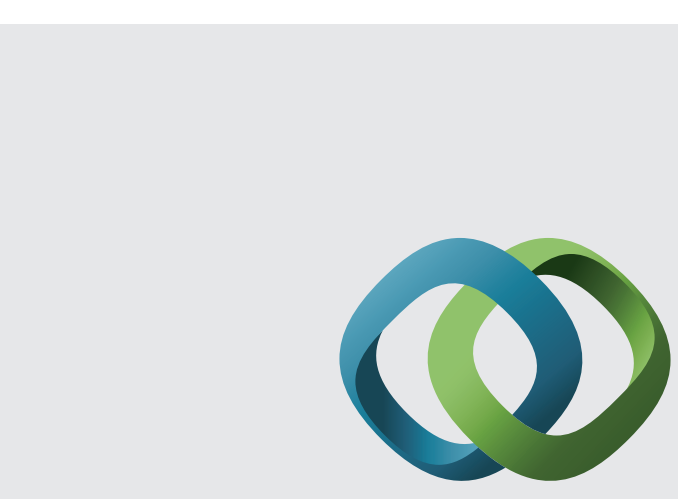

\section{Hindawi}

Submit your manuscripts at

http://www.hindawi.com
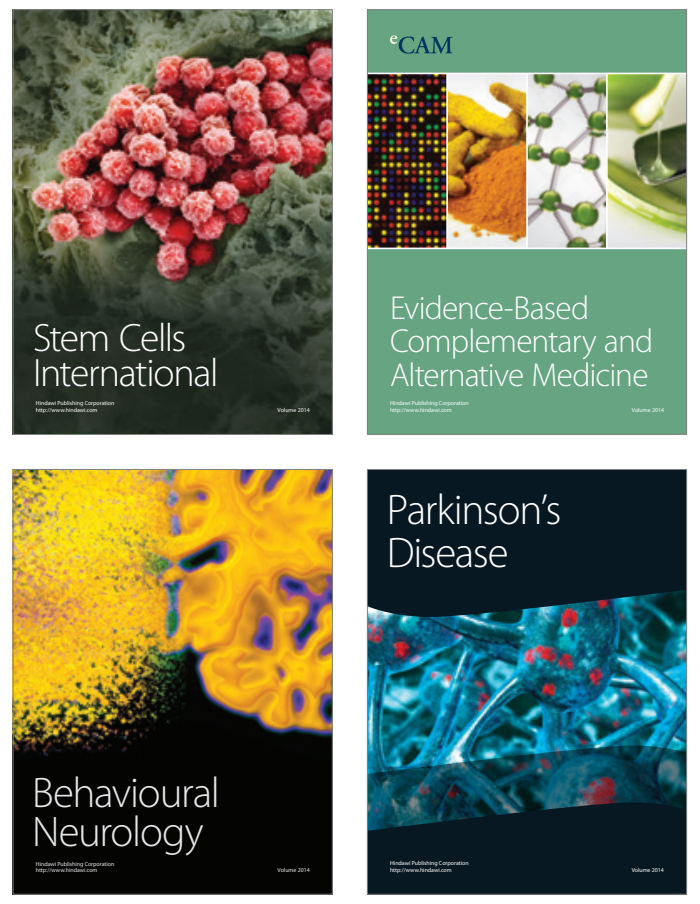
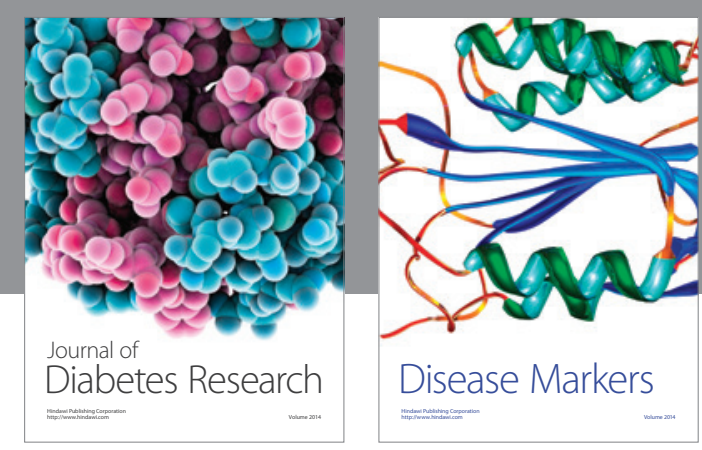

Disease Markers
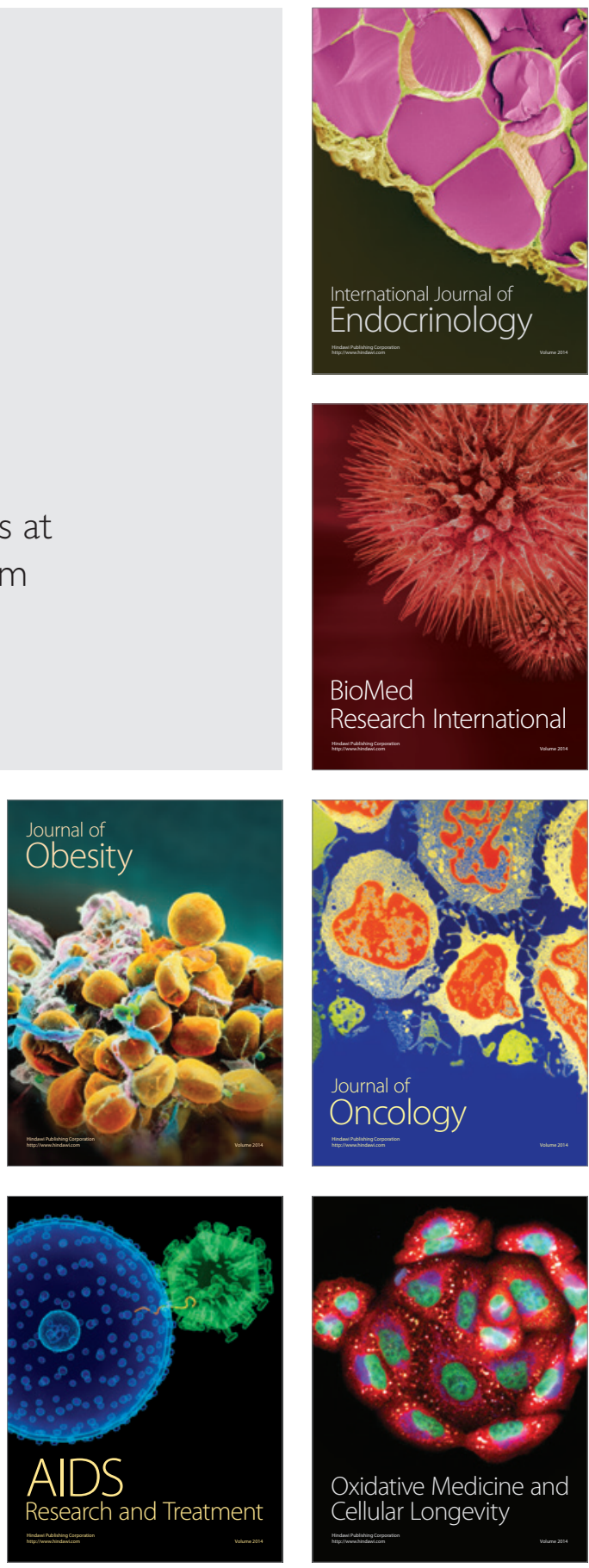